\title{
DETERMINATION OF THE RATIONAL PROFILE FOR THE DISK WORKING TOOL WHEN CULTIVATING OF SOD PODZOLIC SOILS
}

Pavlo ZABRODSKYI, Zhytomyr National Agroecological University, Department of Mechanics and Agroecosystems Engineering, Staryi Blvd 7, Zhytomyr, 10008, Ukraine

Savelii KUKHARETS, Zhytomyr National Agroecological University, Department of Mechanics and Agroecosystems Engineering, Staryi Blvd 7, Zhytomyr, 10008, Ukraine

Andrii ZABRODSKYI, Institute of Agricultural Engineering and Safety, Faculty of Agricultural Engineering, Agriculture Academy, Vytautas Magnus University, K. Donelaičio g. 58, LT-44248 Kaunas, Lithuania, andrii.zabrodskyi3@ gmail.com (corresponding author)

Jonas ĆE்SNA, Institute of Agricultural Engineering and Safety, Faculty of Agricultural Engineering, Agriculture Academy, Vytautas Magnus University, K. Donelaičio g. 58, LT-44248 Kaunas, Lithuania, jonas.cesna@ @du.lt

\begin{abstract}
Maintaining soil fertility is one of the main objectives of agricultural production. An important factor in soil fertility is its optimal structure. For the minimum cultivation of soil widely used equipped with spherical cut-off discs heavy harrows. The purpose of their use, along with others, in the cultivation of heavy soils, for example, chernozems, is the depression of soil boulders and, thus, the optimal structure. In the conditions of intensification of agricultural production under the influence of such soil-working tools in the cultivation of malocontuitive sod-podzolic soils and running gears of mobile equipment, the destruction of the soil structure, the reduction of the number of agronomically valuable water-supply units, and the spread of soil. Thus, for the cultivation of such soils, it is necessary to use discs of another profile, which would ensure the minimum destruction of agronomically valuable watertight aggregates. In order to create such a working body, the process of structuring the agronomically valuable water-conserving aggregates, factors influencing it and analyzing the energy criteria for the formation of a water-tight structure is considered. The features, which arise during mechanical cultivation of soil, influence of cultivation on its structure and features of the stress-strain state of soil are studied. A mathematical model is developed that allows calculating the stress state of the soil and designing the most rational form of disk working bodies. In the conducted studies, the influence of the depth of cultivation, the number of cutouts, the size of the cutout angle and the length of the chord of the projection were studied. On the basis of the developed mathematical model, a rational profile of the disk working organ for the cultivation of small-coupling sod-podzolic soils was obtained and its tests were performed, which showed a decrease of the erosion-dangerous particles of the soil by $(<0,25 \mathrm{~mm}) 24 \%$.
\end{abstract}

Keywords: structure, aggregate, machining, stress, parameters

\section{INTRODUCTION}

The study of structural and mechanical properties of soils and agronomically valuable water-supply units is devoted to a large number of works by such scholars as Goldstein, Shein, Voronin, Kachinsky, Milanovsky, Chestnova and others. Thereby, the study of mechanisms of contact interaction of particles in soil aggregates, which determine the laws of their functioning and formation, deserves special attention. The primary act of structuring is the appearance of contact between adjacent particles of the dispersed phase, and the final result is the emergence of a spatial structure that covers the entire soil profile. The number and nature of contacts are the most important structural characteristics of agronomically valuable water-conserving aggregates. There are three main types of interparticle contacts. These are coagulating liquid contacts, dry point (molecular-point) and condensation (crystallization-cementation), or phase contacts. All three types of contacts take part in the formation of soil aggregates. Along with the specified in the soils, specific cementation-phase contacts are formed. They bind between organomineral fractions of micro aggregates, unaggregated pulverized and sandy soil particles and form water resistant nuclei, which are the main functional unit of aggregate soil structure. In the coagulation fluid contacts between the particles, the thin equilibrium layer of the liquid dispersion medium remains. Thanks to this layer, in the areas of coagulation bonding, the particles can not become closer to each other. Thus, such coagulation structures have reduced strength, creep, even at low shear stresses. In coagulation structures, the contacts between particles are not phase-shaped, but point-like, that is, they correspond to planes in one or more atoms per cell of a crystal lattice. With natural or artificial removal of water from coagulation structures, condensation structures are formed, which are characterized by strong inter-particle coupling. Lehmann suggested that organo-mineral microaggregates are formed by the interaction of polyvalent metals and organic ligands with mineral surfaces (Lehmann, 2007). This is confirmed by studies (Totsche, 2017). In the interaction of organic matter with the mineral part of the soil,cementation and condensation structures of very high strength are formed. Crystallization Copyright (C) 2019 The Authors. Published by Vytautas Magnus University. This is an open-access article distributed under the terms of the Creative Commons Attribution License (CC BY 4.0), which permits unrestricted use, distribution, and reproduction in any medium, provided the original author and source are credited. 
structures have the strongest connections. This is the irreversible coagulation of various colloids with calcium and iron ions. Water-resistant aggregates, which are formed herewith, have very high porosity. Pores are large enough for root hairs, bacteria. Water in these pore spaces is available for plants. Therefore, these are very valuable structures for ensuring soil fertility. Such aggregates of the soil are characteristic of sod-podzolic soils. In soils of heavy mechanical composition, which contain a lot of clay or silt, for example densified chernozems, aggregates with a very dense packing of elementary soil particles are formed. In such aggregates there are almost no pores, and the mobility of water is very small. Such aggregates are not considered to be agronomically valuable.

In the process of mechanical soil cultivation two processes occur simultaneously - the destruction of soil structure and structure formation. Depending on the process prevailing, there is a disruption of the soil, which may lead to an increase in its degradation, or, conversely, its agro-structure is improved and, accordingly, fertility increases. For all other identical conditions, the predominance of a process depends on the type of soil that is cultivated. According to studies (Khan, 2012, Xiao, 2019) under the influence of mechanical stresses that are formed in the soil during mechanical cultivation of soil-working tools, the destruction of a water-resistant frame formed by the adhesion of highly dispersed organo-clay particles occurs. This frame connects, reinforces waterproof aggregate particles in aggregates of soils and determines their water resistance.

The purpose of the work is to determine the rational profile of the disk working tool that improves the quality of tillage by creating the conditions for the formation of watertight aggregates under the appropriate stress state.

\section{MATERIALS AND METHODS}

The study of stress and deformation fields in models of vertical sections of the ground semi-space was performed by mathematical modeling methods with the help of specially developed programs. To determine the optimal model of the parameters of the disk working tool, a full factor experiment was carried out on plan $5^{2}$. Evaluation of the quality of soil cultivation by the proposed instrument was carried out in accordance with generally accepted methods for determining the structural composition of soils (Vadiunina, 1986).

\section{RESULTS AND DISCUSSION}

The process of the destruction of a water-resistant frame is accompanied by the release of aggregate waterresistant particles of different sizes. This regularity characterizing the distribution of destroyed water-resistant particles by fractions is found in aggregates of soils of different genesis, having clayey, heavy-loamy, mediumloamy and sandy granulometric composition, that is characteristic of different types of soils (Khan, 2012). The consequences of this process are different for different soils. If in soils saturated with organic, clay and sludge particles after the destruction of soil aggregates due to mechanical cultivation, their intense formation happen, then on sod-podzolic, which has a high content of coarse dispersed fractions, that is, medium and large sand, gravel, this leads to deterioration of the structural composition of the soil and loss of its fertility. According to studies by M.I. Kartamisheva (Timonov, 2009) mechanical cultivation, improving agrophysical properties during its use, has very serious negative consequences, which accumulate and lead to soil degradation. This is also confirmed by studies (Odarchenko, 2016), which showed that the application of polygonal cultivation in all investigated layers $(0-10,10-20$ and $20-30 \mathrm{~cm})$ leads to a deterioration of the structural state of the soil and a decrease in the number of agronomically valuable aggregates up to $5 \%$ (Table 1 ).

Table 1 . Concentration of agronomically valuable aggregates after dry sifting, $\%$

\begin{tabular}{|c|c|c|}
\hline Cultivation & Soil layer, cm & Average value, $\%$ \\
\hline \multirow{3}{*}{ No-till } & $0-10$ & 77.6 \\
\cline { 2 - 3 } & $10-20$ & 80.9 \\
\cline { 2 - 3 } & $20-30$ & 81.3 \\
\hline \multirow{3}{*}{ Traditional } & $0-10$ & 69.4 \\
\cline { 2 - 3 } & $10-20$ & 72.5 \\
\cline { 2 - 3 } & $20-30$ & 76.9 \\
\hline
\end{tabular}

The development of new constructions of the working tools of soil engineering implements is directed, as a rule, to improve functions such as loosening of soil, crushing ability, easier repair and increase of strength and wear resistance. This also applies to disk excavating part.

Thus, mechanical soil cultivation should be carried out taking into account the type of soil, its properties. When machining sod-podzolic soils, it is necessary to ensure the creation of such a tense state that would ensure the minimum destruction of agronomically valuable watertight aggregates. On such soils, after the destruction of soil structures, to restore them, soil particles need to be brought closer to each other at such a distance to overcome the potential energy barrier (Vadiunina, 1986, Shen, 2017). Under natural conditions, the overcoming of this energy barrier and the formation of water-proof aggregates of the soil happens due to the processes of hydration and dehydration, freezing and thawing of the soil. An important role here is played by the roots of plants, which mechanically disassemble the soil mass. At the same time, the soil creates a tense state through which the soil particles are displaced, converge to the required distance, and in which there are the most favorable conditions for the electrostatic interaction of humus acids with lateral cleavage of clay particles and the formation of water-proof aggregates of the soil, taking into account that there is an opening micro aggregates of clay particles. 
The estimation of the ability of different types of soils to form water-based aggregates on the basis of energy criteria was studied by $\mathrm{K}$. Yu. Khan and is given in Table 2.

Table 2. Energy criteria characterizing the conditions for the formation of a water-resistant structure - a framework in the micro aggregates of the soil

\begin{tabular}{|c|c|c|c|c|}
\hline \multirow{2}{*}{ Soils } & \multirow{2}{*}{ Humus, \% } & \multirow{2}{*}{$\mathbf{P}_{\mathbf{c}}, \mathbf{k P a}$} & \multicolumn{2}{|c|}{$\mathbf{D}=\mathbf{0 , 2} \boldsymbol{\mu m}$} \\
\cline { 4 - 5 } & & & $\boldsymbol{u}_{\mathbf{z v}} \cdot \mathbf{1 0}^{\mathbf{- 1 9}} \mathbf{J}$ & $\boldsymbol{U}_{\left(\boldsymbol{h}_{\mathbf{0}}\right), \mathbf{M J} / \mathbf{m}^{\mathbf{2}}}$ \\
\hline Light gray forest & 3.4 & 9.956 & 1.35 & 4.3 \\
\hline Gray forest & 4.5 & 14.205 & 1.53 & 4.9 \\
\hline Dark gray & 7.8 & 18.363 & 1.72 & 5.5 \\
\hline Typical Chernozems (black soils) & 8.4 & 18.469 & 1.74 & 5.5 \\
\hline
\end{tabular}

In these studies, the value of $\boldsymbol{u}_{z v}$ was determined on the basis of experimental data characterizing the longterm strength of the structure of water-resistant aggregates. The value $\boldsymbol{U}_{\boldsymbol{c}}$ characterizes the critical depth of the initial minimum, in which coagulation is thermodynamically disadvantageous. In a disperse system, $\boldsymbol{U}\left(\boldsymbol{h}_{\mathbf{0}}\right)<\boldsymbol{U}_{\boldsymbol{c}}$ establishes the equilibrium between processes of peptization and coagulation. The critical value of the energy of intermolecular attraction $\boldsymbol{U}_{\boldsymbol{c}}$ for $\boldsymbol{h}=\boldsymbol{h}_{\mathbf{0}}$ for particles with $\boldsymbol{r}=\mathbf{0 , 1} \mu \mathrm{m}$ was $0.7 \mathrm{~mJ} / \mathrm{m}^{2}$. It is much smaller than the value $\boldsymbol{U}\left(\boldsymbol{h}_{\mathbf{0}}\right)$, determined in the investigated soils (Table 1).

The approaching of soil particles to each other and, thus, an increase in the number of contacts between particles is possible also due to the creation of an appropriate stressed state due to mechanical soil cultivation. This is proved by experiments carried out with compression pressing of samples (Liashenko, 2006, Milkevych, 2018). Depending on the type of tillage tool and the type of applied load, the deformation and destruction of the soil can occur according to the following schemes: separation, when the cracks differ in relation to one another; transverse displacement when the surface of the crack slide one after the other in a transverse direction; longitudinal displacement when the surface of the crack slide one after another in the longitudinal direction. The maximum possible level of formation of agrarian structural formations is possible under the conditions of structural deformation by the separation breaking stresses corresponding to scheme 1 . When the soil is cultivated by disk working tools, the scheme 3 is implemented, which, although, in the classical version does not contribute to the formation of aggregate formations, but also does not lead to significant their destruction. This is confirmed by the results of the research (Kukharets, 2018).

The breaking stresses and deformations at any point in the deformed zone are interconnected by the stressstrain relationship. The deformation dependence on the stress is rather complex and should be determined experimentally, as the values of stresses on the edges of the selected bulk soil element $\sigma_{I}, \sigma_{I I}, \sigma_{I I I}$ and their directions are variables. While working with traditional working tools of inert sod-podzolic soils, tangential stresses are the prevailing stresses in the soil (Korniienko, 2016), which contribute to soil loosening. However, in terms of the formation of soil aggregates, the essential condition is that the main stresses $\left(\sigma_{I}+\sigma_{I I}\right)_{\max } \rightarrow \max$. As calculations show, during the cultivation of soil with disk implements with cutouts in the soil there is a complex stressed state with the number of zones of contact loads equal to the number of working protrusions. The mathematical model developed on the basis of the M. Flaman problem allows us to calculate the stress state of the soil and obtain its graphic representation (Fig. 1) for several zones of contact loads depending on the distance between the projections $\mathbf{2} \boldsymbol{a}$ and the load size $\boldsymbol{G}$ :

$$
\begin{aligned}
\sigma_{x} & =-\frac{G}{\pi}\left\{\frac{x^{3}}{\left[x^{2}+(y-a)^{2}\right]^{2}}+\frac{x^{3}}{\left[x^{2}+(y+a)^{2}\right]^{2}}\right\} \\
\sigma_{x} & =-\frac{G}{\pi}\left\{\frac{x(y-a)^{2}}{\left[x^{2}+(y-a)^{2}\right]^{2}}+\frac{x(y+a)^{2}}{\left[x^{2}+(y+a)^{2}\right]^{2}}\right\} \\
\tau_{x y} & =-\frac{G}{\pi}\left\{\frac{x^{2}(y-a)}{\left[x^{2}+(y-a)^{2}\right]^{2}}+\frac{x^{2}(y+a)}{\left[x^{2}+(y+a)^{2}\right]^{2}}\right\}
\end{aligned}
$$

The total load on the disk during the study was assumed constant and is $630 \mathrm{~N}$, which corresponds to the normal value for the disc harrow BDT-6. The maximum value of the sum of the principal stresses at a plane stress state of the soil half-space at depths of 20,40,60, 80, 100, and $120 \mathrm{~mm}$ was calculated.

As a result of the conducted studies, it was found that the complete separation of high-pressure nuclei in the soil occurs at a distance between the cuts greater than 90-100 $\mathrm{mm}$. At smaller distances, a disk with cuts from the point of view of a tense state works to a large extent as a disk without cutouts. The optimal construction of the disk working tool is a disk with a number of cutouts equal to 8 , the angle between the side surfaces of 


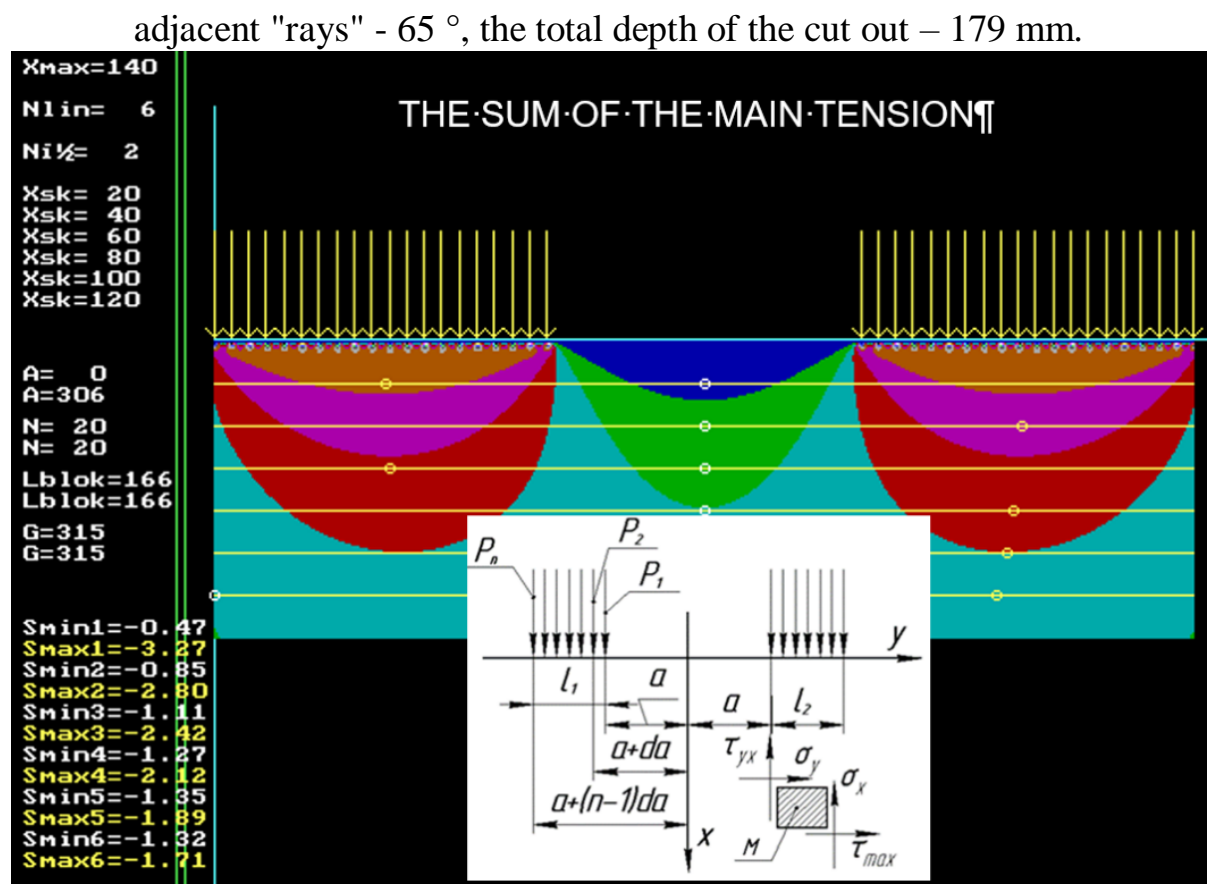

$\mathrm{P} 1, \mathrm{P} 2, \ldots, \mathrm{Pi}$ - are the value of corresponding unit forces, $\mathrm{H} ; \mathrm{a}-$ is the distance of block beginning from the beginning of coordinates, $\mathrm{m} ; \mathrm{da}-$ is spacing among forces in a block, $\mathrm{m} ; 11,12$ - is blocks' width, $\mathrm{m} ; \sigma \mathrm{x}, \sigma \mathrm{y}, \tau \mathrm{yx}$ - are normal and tangent tenses in elementary semi-space M, $\mathrm{PA} ; \mathrm{n}-$ is a number of forces in a block of distributed load.

Figure1. Graphic representation of the stressed state of the soil, obtained using a mathematical model

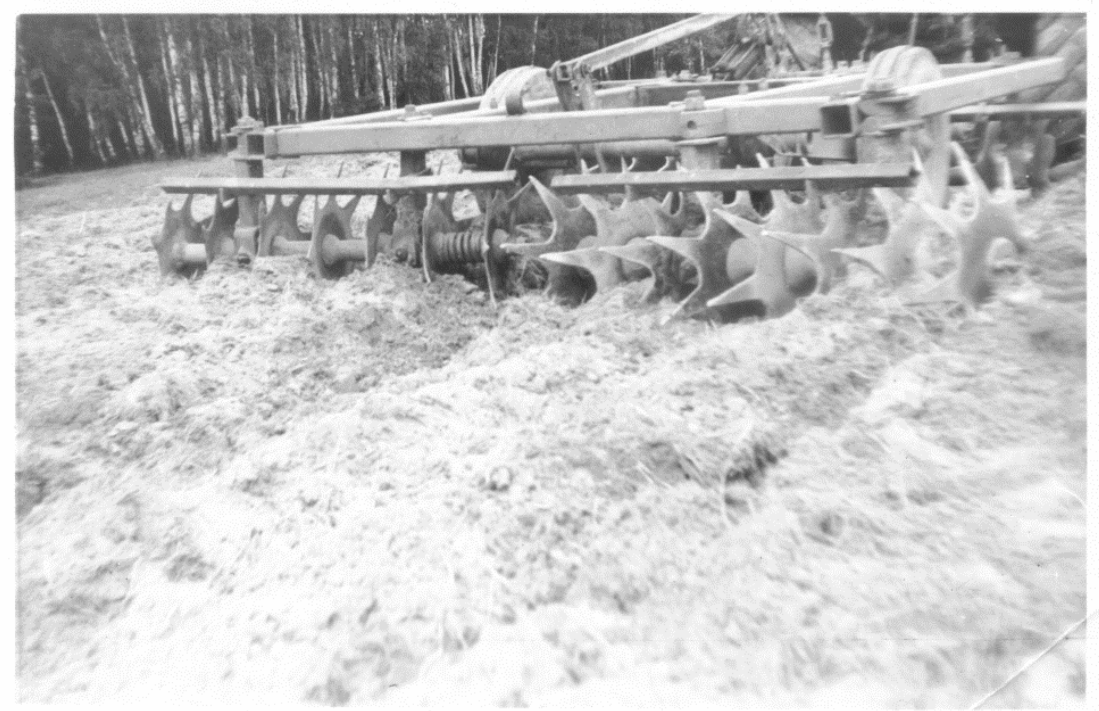

Figure 2. The developed construction of the working tool

Deployment of the developed disk working tool allowed to improve the quality of the treated soil, to bring the density of the arable layer to $1.16 \ldots 1.25 \mathrm{~g} / \mathrm{cm}^{3}$, which is $2.4-4.2 \%$ better than the standard discs worked, reduce the amount of erosion - dangerous particles $(<0,25 \mathrm{~mm})$ by $24 \%$.

\section{CONCLUSIONS}

1. In the cultivation of lowly cohesive sod-podzolic soils by traditional working tools, the processes of destruction of the structure of the soil are dominated by the processes of structuring. This leads to a decrease in the number of agronomically valuable water-conserving aggregates, increased dust particles, soil degradation and reduced fertility.

2. Existing disc working tools do not take into account peculiarities of cultivation of such soils in terms of preservation of agronomically valuable water-conserving aggregates.

3. The stressed state of cultivation of small-coupling sod-podzolic soils should provide conditions for the soil particles to be brought closer to such a distance in order to overcome the potential energy barrier and create conditions for the formation of agronomically valuable water-conserving aggregates. 
4. The researches made it possible to obtain a rational profile of the disk working tool for the cultivation of smallcoupling sod-podzolic soils for the BDT-6 disc harrow: number of cutouts equal to 8 , the angle between the side surfaces of adjacent "rays" $-65^{\circ}$, the total depth of the cutout - $179 \mathrm{~mm}$.

\section{REFERENCES}

1. Khan K.Y. 2012. Energy Characteristics of Water Resistance of Soil Aggregates. Doctoral dissertation, Pushchyno, 54 p. (In Russian).

2. Korniienko S.I., Pashchenko V.F., Melnyk V.I. 2016. Development of a method for constructing mathematical models of soil condition under the influence of a wedge. Vostochno-Evropeiskyi zhurnal peredovblkh tekhnolohy, Vol. 5 (83). (In Russian). https://doi.org/10.15587/1729-4061.2016.79912

3. Kukharets S., Golub G., Biletskii V., Medvedskyi O. 2018. Substantiation of the parameters of the disk-knife working body and the study of its work. Research in Agricultural Engineering, Vol. 64, No. 4, pp. 195-201. https://doi.org/10.17221/87/2017-RAE

4. Lehmann J., Kinyangi J., Solomon D. 2007. Organic matter stabilization in soil microaggregates: implications from spatial heterogeneity of organic carbon contents and carbon forms. Biogeochem, Vol. 85, pp. 45-57. https://doi.org/10.1007/s10533-007-9105-3

5. Liashenko P.A. 2006. The nature of the compressibility of soils and soils. Polytematycheskyi setevoi elektronnyi nauchnyi zhurnal Kubanskoho hosudarstvennoho ahrarnoho unyversyteta, Vol. 19, pp. 9-28. (In Russian).

6. Milkevych V., Munkholm L. J., Chen Y., Nyord T. 2018. Modelling approach for soil displacement in tillage using discrete element method. Soil and Tillage Research, Vol. 183, pp. 60-71. https://doi.org/10.1016/j.still.2018.05.017

7. Odarchenko O.M., Tanchyk S.P. 2016. Influence of the shelf and "zero" work on the structure of the soil in the field of barley of the wild right-bank forest-steppe of Ukraine. Ahrobiolohiia Vol. 1, pp. 36-41. (In Ukrainian).

8. Shen, C., Bradford, S., Wang, Z., Huang, Y., Zhang, Y., \& Li, B. 2017. DLVO Interaction Energies between Hollow Spherical Particles and Collector Surfaces. Langmuir, Vol. 33(40), pp. 10455-10467. https://doi.org/10.1021/acs.langmuir.7b02383

9. Timonov V.Y., Chernyshova N. M., Balabanov S.S., Kartamyshev N.I. 2009. Mechanical processing and agrophysical properties of soil. Vestnyk Kurskoi hosudarstvennoi selskokhoziaistvennoi akademii. Vol. 6, pp. 53-57. (In Russian).

10. Totsche K. U., Amelung W., Gerzabek M. H., Guggenberger G., Klumpp E., Knief C., Kögel-Knabner I. 2017. Microaggregates in soils. Journal of Plant Nutrition and Soil Science, 181(1), pp. 104-136. https://doi.org/10.1002/jpln.201600451

11. Xiao S.-S., Ye, Y.-Y., Xiao D., Chen W.-R., Zhang W., Wang K.-L. 2019. Effects of tillage on soil N availability, aggregate size, and microbial biomass in a subtropical karst region. Soil and Tillage Research, Vol. 192, pp. 187-195. https://doi.org/10.1016/j.still.2019.05.006

12. Vadiunina A.F., Korchahina Z.A. 1986. Methods of studying the physical properties of soils. Ahropromizdat, Moscow.(In Russian). 